\title{
Death anxiety, death reflection and interpersonal communication as predictors of social distance towards people infected with COVID
} 19

\author{
Petru Lucian Curșeu ${ }^{1,2}$ (D) Andra Diana Coman ${ }^{1} \cdot$ Anton Panchenko $^{1} \cdot$ Oana Cătălina Fodor ${ }^{1} \cdot$ Lucia Rațiu $^{1}$
}

Accepted: 5 November 2020 / Published online: 4 March 2021

(C) Springer Science+Business Media, LLC, part of Springer Nature 2021

\begin{abstract}
Our study investigates several antecedents and consequences of negative emotional reactions to the COVID-19 pandemic in a cross-national sample of 737 participants. Our results show that COVID-19 anxiety and negative mood are positively predicted by death anxiety and the use in communication of general COVID-19 information. Death reflection reduces negative mood in relation to COVID-19 and attenuates the positive association between death anxiety on the one hand and the negative mood and anxiety in relation to COVID-19 on the other hand. The use of humoristic information about COVID-19 reduces anxiety and social distance towards people infected with COVID-19 and also attenuates the positive association between the use in communication of general COVID-19 information and negative mood in relation to COVID-19. Our results also show that the association between death anxiety and social distance towards those infected with COVID-19 is mediated by anxiety and negative mood in relation to COVID-19. Finally, the association between the use of COVID-19 information in interpersonal communication and social distance is mediated by anxiety and negative mood in relation to COVID-19. The study thus reveals specific insights for tailored interventions to reduce negativity towards people infected with COVID-19.
\end{abstract}

Keywords COVID-19 $\cdot$ Humor $\cdot$ Communication $\cdot$ Social distance $\cdot$ Discrimination $\cdot$ Death anxiety

\section{Introduction}

The COVID-19 pandemic is one of the important global anxiety-triggering events of the last decades. People across the globe are informed about the increasing death toll as the pandemic progresses and are reminded of the frailty of human

Petru Lucian Curşeu

petrucurseu@psychology.ro

Andra Diana Coman

andracoman@psychology.ro

Anton Panchenko

antonpanchenko@psychology.ro

Oana Cătălina Fodor

oanafodor@psychology.ro

Lucia Rațiu

luciaratiu@psychology.ro

1 Psychology Department, Babeş - Bolyai University, 37 Republicii Street, 400015 Cluj-Napoca, Romania

2 Department of Organization, Open University of the Netherlands, Heerlen, The Netherlands existence. Such a global event triggers, no doubt, thoughts related to ones' own mortality. Terror Management Theory (TMT, Solomon et al., 1991) has extensively explored the consequences of mortality salience and showed that individuals engage various coping mechanisms aimed at restoring self-esteem that is threatened by mortality cues. One such mechanism is the worldview defense (Harmon-Jones et al., 1997) that describes the accentuation of interpersonal preferences for individuals who share the same worldview and the rejection of those who hold different worldviews. The worldview defense activated by mortality salience is therefore expected to bolster discrimination and intergroup conflict (Greenberg \& Kosloff, 2008). We build on the mortality salience hypothesis of the TMT and on the activation of worldview defenses to argue that the global COVID-19 pandemic is a mortality cue with important implications for psychological well-being and social relations, in particular with the ones infected with the virus.

Death anxiety is a stable individual propensity to experience negative emotions stemming from one's existential concerns related to mortality (Sliter et al., 2014). Death reflection is a stable individual tendency to engage in "deliberate cognitive processing of mortality that focuses on the positive aspects of death, which 
encompasses concrete behavioral intentions to realize such positive aspects" (Yuan et al., 2019, p. 419). As opposed to death anxiety that focuses on negative emotions triggered by mortality cues, death reflection describes the cognitive attempts to give higher order meaning to death, put life in context and live meaningfully. We build on the idea that stable personality traits reflect accumulated state-like behavioral tendencies, emotional experiences and evaluative tendencies (Fleeson, 2001) to argue that death anxiety reflects a systematic tendency to experience negative emotionality related to death-threatening nature of stressors in the environment, while death reflection reveals systematic cognitive efforts of putting death-threatening stressors in context and ultimately reduce the anguish of death (Yuan et al., 2019). In line with this conceptualization, the COVID-19 pandemic brings forth mortality cues that are more likely to trigger negative emotionality and state-like anxiety for those scoring high rather than low in death anxiety as well as for those scoring low rather than high in death reflection as individual differences.

In the context of widely spread mortality salience cues associated with the COVID-19 pandemic, our paper aims to explore the antecedents and social consequences of negative emotionality (anxiety and negative mood) in relation to COVID-19. First, we set out to test the influence of interpersonal communication as well as of individual differences in death anxiety and death reflection on negative emotionality related to COVID-19 (state anxiety and negative mood). Second, we test the mediating role of negative emotionality in relation to COVID-19 in the relationship between interpersonal communication and individual differences in death anxiety on the one hand and social distance towards people infected with COVID-19 on the other hand. We extend existing research in several ways. First, we build on previous research on the interplay between death anxiety and death reflection (Yuan et al., 2019) and show that death reflection (as a trait) impacts on the strength of the association between death anxiety (as a trait) and COVID-19 anxiety and negative mood (as emotional states). Second, we test the interplay between the use of humoristic and general COVID-19 communication on negative emotionality in relation to COVID-19 and pinpoint the role of using humor in communication as an anxiety buffer. Finally, we build on the TMT research to show that the discrimination of the ones infected with COVID-19 stems from the mortality cues and anxiety generated by the pandemic.

\section{Theory and Hypotheses}

A key tenet of TMT is the assertion that thoughts related to death trigger intense anxiety and people are motivated to reduce this anxiety (Solomon et al., 1991). Death anxiety is therefore the result of emotional processing related to one's own demise (Pyszczynski et al., 1999). Research using direct and indirect emotional measures in relation to death priming show that death anxiety is an interpersonal tendency of negative emotional processing concerning death-related cues
(Pettigrew \& Dawson, 1979). Novel insights into the cognitive and emotional correlates of mortality salience recognize the role of death reflection, resulting from an analytical rather than emotional processing of death-related thoughts (Yuan et al., 2019). If death anxiety is associated with fear and negative emotionality, death reflection focuses on rationalization and analytic cognitions that position mortality in relation to meaningful life experiences. This line of research argues that the awareness of death increases the focus on meaningful life experiences and, as such, it might be perceived in a positive way (Yuan et al., 2019). We argue that these two stable interpersonal differences are key antecedents of negative emotionality in relation to the COVID-19 pandemic (anxiety and negative mood).

Research on the emotional reactions to the pandemic shows that having relatives infected with COVID-19 increased anxiety in Chinese students (Cao et al., 2020) and the COVID-19 anxiety has at its core concerns related to personal and family health (Li et al., 2020). Moreover, comparative analyses of social media posts before and after the declaration of COVID-19 emergency situation in China showed a significant increase in emotions associated with anxiety and social risktaking and a decrease in positive emotions (Li et al., 2020). Also, after COVID-19 was recognized as a pandemic and concerns about public health were widely communicated in mass media and via the internet, Chinese respondents reported a significant level of psychological distress related to the outbreak of COVID-19 in China (Wang et al., 2020). To conclude, research to date shows that the COVID-19 pandemic generated anxiety-like states characterized by a preoccupation with one's own health and the health of the close relatives. As indicators of negative emotionality, we distinguish between COVID-19 anxiety and the negative mood associated with COVID-19. Negative mood refers to a set of transient diffuse emotional states (Lazarus, 1991) related to COVID-19 (given the nature of the target we expect that these emotional states are negative), while anxiety describes feelings of perceived threat, uncertainty, nervousness that can be anticipatory in nature, resulting from the cognitive appraisal of a particular event or stimulus (Lazarus, 1991).

Stable personality traits can be conceptualized as density distributions of trait-congruent behaviors or states (Fleeson, 2001), therefore stable individual differences in anxiety (anxiety as a trait) reflect individual differences in sensitivity to threatening situations (Schmukle \& Egloff, 2004). In a plausible causal chain, traits as stable individual differences are expected to predict states or tendencies to react to environmental stimuli. Stable individual differences as death anxiety and death reflection impact on the COVID-19 anxiety as a state, such that due to the mortality salience triggered by COVID-19, death anxiety (as trait) has a positive association with COVID-19 anxiety and negative mood (states), while death reflection as a tendency to focus on meaningful life 
experiences has a negative association with COVID-19 anxiety and negative mood (as states). Previous research showed that death reflection buffers the association between mortality salience cues and well-being (Sliter et al., 2014), therefore the analytical rationalizations associated with death reflection could act as a protective factor against the negative emotionality associated with death anxiety. With respect to the negative emotionality related to COVID-19 we hypothesize that:

- H1: Death anxiety fosters a COVID-19 anxiety state (H1a) and negative mood in relation to COVID-19 (H1b).

- H2: Death reflection reduces the COVID-19 anxiety state (H2a) and the negative mood in relation to COVID-19 (H2b).

- H3: Death reflection reduces the positive association between death anxiety and the COVID-19 anxiety (H3a) and negative mood (H3b).

Public communication most often conveys information on the COVID-19 pandemic stressing its death toll and therefore COVID-19 is perceived as a strong mortality cue. We therefore expect that the frequency of using ideas related to COVID-19 in interpersonal communication increases the salience of the mortality cues associated with the pandemic and will ultimately spur the state of anxiety and negative emotionality experienced in relation to COVID-19. In a review on previous research on the relation between exposure to information about community-wide crises and mental health consequences, Garfin et al. (2020) report a positive effect on anxiety and such a positive association was found for COVID-19 communication as well (Gao et al., 2020). Communication however may also alleviate concerns related to particular threats, especially if humor is used. Using humor in communication releases emotional tension and is a protective factor against stress (Lynch, 2002). In an experimental study, Ford and collaborators (2012) showed that exposure to humoristic communication decreases test-related anxiety and ultimately performance, while in the health domain, Nabi (2016) showed that perception of humor in communication reduces anxiety in relation to taking cancer self-exams. Exposure to humor in communication prior to dissection-related educational activities reduces the level of anxiety and disgust reported by medical students (Randler et al., 2016). The use of humor in communication reduces the stress associated with healthcare work and ultimately increases well-being at work (Bhattacharyya et al., 2019). In the case of COVID-19 related communication we therefore expect that the overall prevalence of COVID-19 topics in interpersonal communication is conducive to state anxiety and negative mood in relation to the pandemic, while the use of humoristic COVID19 related topics in interpersonal communications has a buffering effect both directly as well as by attenuating the positive association between overall communication and COVID-19 emotional experiences. We therefore hypothesize that:
- H4: The use of general information concerning COVID19 in interpersonal communication is positively associated with COVID-19 anxiety (H4a) and negative mood (H4b).

- H5: The use of humoristic information about COVID-19 in interpersonal communication is negatively associated with COVID-19 anxiety (H5a) and negative mood (H5b).

- H6: The use of humoristic information about COVID-19 in interpersonal communication alleviates the positive association between the use of general information and COVID-19 anxiety (H6a) and negative mood (H6b).

COVID-19 was oftentimes labeled as a "foreign virus" in public communication (Sorokowski et al., 2020). The same is valid for the pandemic in Romania. Allegedly, in March alone, 250.000 Romanians from abroad (seasonal workers with poor work arrangements and healthcare insurance) returned to Romania, most of them from Italy and Spain. As a substantial number of confirmed corona cases originated from Italy and Spain, a negative attitude towards people infected with COVID-19 shortly emerged, boosted by the media reports concerning the people violating quarantine regulations. Similarly, in Kazakhstan the origin of viral infections with COVID-19 were placed in neighboring China. In such a context it is important to understand the antecedents of discrimination towards people infected with COVID-19 as embedded in broader intergroup relations.

Research using TMT extensively shows that mortality salience bolsters the world view and increases attraction to the ones that share the same values, opinions and attitudes (worldview) and generates the rejection of those with different worldviews (Greenberg et al., 1990). Overall, substantial empirical evidence supports the positive association between mortality salience and discrimination towards different others in a variety of experimental settings and cultural contexts (Greenberg \& Kosloff, 2008). The mortality salience hypothesis in TMT has clearly an underlying coping function with the anxiety generated by the idea of one's own mortality. When mortality salience is activated, people tend to relate to others that share the same worldview because they provide ample self-validation opportunities that restore their selfesteem and their positive emotionality (Greenberg \& Kostloff, 2008). On the contrary, when mortality salience is high, people tend to reject others that hold different worldviews because the lack of belief consensus is threatening for their self-esteem and psychological well-being (Greenberg et al., 1990). As argued before, the anxiety related to COVID-19 is clearly an anxiety-generating mortality cue and we expect that COVID-19 anxiety has a positive association with discrimination towards infected people.

- H7: COVID-19 anxiety positively predicts social distance towards people infected with COVID-19. 
Although TMT emphasized that the mortality salience manipulations are not directly associated with negative affect (affect-free claim Pyszczynski et al., 1999), Lambert et al. (2014) showed that the manipulation of mortality salience generates substantial emotional distress and that negative emotionality explains significant variance in the mortality salience effects. Moreover, a study in which the experienced negative mood is attributed to the target, negative mood predicts the magnitude of discrimination (Sechrist et al., 2003). Broudy et al. (2007) showed that daily variations in mood intensity predict discrimination intentions and these results are in line with the affect as information theory (Schwarz \& Clore, 2003) showing that people use mood valence as an information processing cue. In the COVID-19 context, people use the negative mood generated by the pandemic as a cue to distance themselves from the ones infected. In line with these arguments we hypothesize the following:

- H8: Negative mood in relation to COVID-19 has a positive association with social distance towards people infected with COVID-19.

In several experimental studies, Florian and Mikulincer (1997) showed that negative evaluations towards social transgressions are amplified when the transgression fits the prompted fear of death. Related to the COVID-19 pandemic a hypothesis derived from TMT would state that the negative emotionality related to COVID-19 mediates the association between fear for death and the social distance towards the ones infected with COVID-19. In other words, the trait anxiety related to one's mortality fosters the emergence of state anxiety and negative mood in relation to COVID-19 and, in turn, leads to discrimination against people infected with COVID-19.

- H9: COVID-19 anxiety and negative mood mediate the association between death anxiety and social distance towards people infected with COVID-19.

We have argued earlier that the use of general COVID-19 information in interpersonal communication increases negative emotionality while the use of humoristic communication decreases the negative emotionality in relation to COVID-19. Based on the previous arguments stating the positive association of negative mood and discrimination, we argue that the effect of interpersonal communication on discrimination towards those infected with COVID-19 is mediated by anxiety and negative mood.

- H10: COVID-19 anxiety and negative mood in relation to COVID-19 mediate the association between the COVID19 communication and social distance towards those infected.

\section{Methods}

\section{Sample and Procedure}

We have used a sample of 736 participants in a larger online survey related to the COVID-19 pandemic. The sample consisted of 556 Romanian speaking participants from Romania with an average age of around 35 years old (432 females) and 181 Russian speaking participants from Kazakhstan with an average age of about 34 years old (114 females). Participants were selected using a convenience sampling procedure with a snowball instruction (people were asked to distribute the link with the survey to others in their own network) and the survey was distributed at the end of March and beginning of April 2020 right after Romania and Kazakhstan declared a state of emergency and implemented public measures aimed at reducing the public impact of the pandemic. Participants were informed that their participation is anonymous, they could withdraw from the study at any moment and all data would be treated with confidentiality. We collected demographic data on age and gender, yet participants who did not want to provide such information were allowed to skip these questions. Study materials were disseminated in two languages Romanian and Russian. For the current study we have used part of larger survey and we have sliced the data in line with the recommendations presented in Kirkman and Chen (2011), such that except for demographic and control variables there is no overlap in variables used in the current study and another study derived from the same survey.

\section{Measures}

Exchange of general information about COVID was evaluated using a single item: "How often do you exchange informative insights about coronavirus with your family and friends". Answers were recorded on a seven-point Likert-type scale $(1=$ never to $7=$ several times every day $)$.

Exchange of humoristic messages about COVID-19 was also evaluated using a single item: "How often do you make jokes with your family and friends about coronavirus". The same anchors were used as for the exchange of general information about COVID-19. COVID-19 communication was evaluated with single items and although single item measures have important limitations, items referring to clear behaviors, using clear behavioral anchors (like in our case frequency of using a particular form of interpersonal communication), yield reliable estimates for the evaluated constructs (Wanous, \& Reichers, 1996; Wanous et al., 1997).

COVID-19 anxiety was evaluated with three items that have used emotions reported in previous investigations of anxiety (Belmi \& Pfeffer, 2016; Spielberger \& Reheiser, 2009): "Thinking of coronavirus (COVID-19) is stressful to 
me", "It is upsetting to think of coronavirus (COVID-19)", "Coronavirus (COVID-19) is worrying me". Cronbach's alpha for this scale is .89 and the omega score, derived from confirmatory factor analysis (Hayes \& Coutts, 2020), is .89 reflecting a good internal consistency if the scale. The factor loadings for the three items are $.93, .83$ and .79 respectively indicating unitary factor structure of the scale.

Negative mood in relation to COVID-19 was evaluated with a single item: "Mood describes one's general emotional experience likely to be triggered by a particular stimulus or event and moods have either a positive or negative valence. How would you describe your general mood in relation to the coronavirus (COVID-19) situation?". The item was developed in line with the suggestion made by Cheung and Lucas (2014) and answers were recorded on a four-point Likert-type scale ( 1 very good all the time; 2 mostly good; 3 mostly not good; 4 not good all the time).

Death anxiety was evaluated with a six-item scale described in Belmi and Pfeffer (2016), examples of items included: "I am very much afraid to die". Answers were recorded on a five-point Likert-type scale ranging from $1=$ fully disagree to $5=$ fully agree. Cronbach's alpha for this scale is .95 , while the omega score, based on the results of a confirmatory factor analysis (Hayes \& Coutts, 2020), is .96 with factor loadings for items varying from .83 to .93 indicating unitary factor structure of the scale and a good internal consistency.

Death reflection was evaluated with a 15 -item scale introduced by Yuan et al. (2019). The scale has five dimensions for evaluating death reflection thoughts, namely: motivation to help ("When I think about death, I feel like I should do more for the world"), motivation to live ("When I think about death, I make plans for my life"), putting life in perspective ("When I think about death, I can let go of the little problems"), personal legacy ("When I think about death, I think about what legacy I will have left behind") and connection to others ("When I think about death, I want to spend more time with the people I care about"). All these items reflect dimensions on which people reflect on life in relation to its finite nature. The unrotated principal component analysis reveals five factors with eigenvalues higher than 1 , covering close to $80 \%$ of the variance in scores. The unrotated component matrix shows that all items load on a dominant factor score, yet when an oblimin rotation is used, the 15 items load on their respective dimensions as described in Yuan et al. (2019). Cronbach's alpha reflects a good internal consistency for all dimensions namely: .88 for motivation to help, .84 for motivation to live, .86 for putting life in perspective, .85 for personal legacy and .87 for connecting with others. Cronbach's alpha for the overall scale is .87 indicating a good internal consistency. However, as this scale includes several dimensions, we use the procedure and macros presented in Hayes and Coutts (2020) to compute the omega for this scale based on the results of a confirmatory factor analysis, procedure that yields an omega of .87 a good overall internal consistency of the scale. The inter- correlations among the five dimensions range from .23 (between legacy and motivation to live) to .49 (between motivation to help and motivation to live), and are aligned with the ones reported in Yuan et al. (2019). Given the fact that all items load on a dominant factor score and the overall good internal consistency of the overall scale, the death reflection score was computed as average item score and used in subsequent analyses.

Social distance towards people infected with COVID-19 was used as an indicator of discrimination. Social distance was measured using a Bogardus scale that typically asks participants to express their acceptance of others in various degrees of social proximity varying from as close as marriage to the most extreme situation of not accepting them in the country. The social distance scale has a long history in the study of intergroup relations, it was originally created to evaluate prejudice in inter-ethnic relationships and it is currently one of the frequently used measures of prejudice and discrimination tendencies (Curşeu et al., 2007; Wark \& Galliher, 2007). The items of the scale are organized so they reflect decreasing levels of closeness towards members of particular social categories. The scale used in this study included seven items and although typically the items are scored in a dichotomous way (yes/no answers), for our study the answers were recorded on a five-point Likert-type scale $(1=$ strongly disagree to $5=$ strongly agree $)$. We further build on the suggestions from Mather et al. (2017) in creating a weighted score that illustrates social distance. We have first recoded all items reflecting social distance and then we have used the weighing scheme introduced in Mather et al. (2017) to compute the final social distance scores. Cronbach's alpha for the recoded items is .88 showing a good internal consistency of the scale. A high score for the social distance scale reflects a tendency to tolerate low social closeness, intimacy and ultimately reject people infected with COVID-19. As such, the scale does not refer to physical distance emphasized in the social distancing messages associated with the COVID-19 pandemic, but rather a sense of psychological distancing, prejudice against, and rejection of people infected with COVID-19.

We have included several control variables in our study as well. Gender was coded as a dummy variable $(0=$ males, $1=$ females), education evaluated on a six interval scale (from $1=$ primary school, $2=$ intermediate secondary education, $3=$ higher secondary education, $4=$ intermediate vocational education, $5=$ higher vocational education, $6=$ university education), age evaluated as a continuous variable, country of origin (evaluated as a dummy variable $1=$ Romania, $0=$ Kazakhstan) and the day in which the survey was completed (continuous variable ranging from 1 to 17).

\section{Results}

Table 1 includes the means, standard deviations and correlations for the variables included in our study. 
Table 1 Means, standard deviations and correlations

\begin{tabular}{|c|c|c|c|c|c|c|c|c|c|c|c|c|c|c|c|}
\hline & $\begin{array}{l}\text { Mean } \\
\text { RO }\end{array}$ & $\begin{array}{l}\mathrm{SD} \\
\mathrm{RO}\end{array}$ & 1 & 2 & 3 & 4 & 5 & 6 & 7 & 8 & 9 & 10 & 11 & $\begin{array}{l}\text { Mean } \\
\text { KZ }\end{array}$ & $\begin{array}{l}\mathrm{SD} \\
\mathrm{KZ}\end{array}$ \\
\hline 1. Age & 35.06 & 10.42 & 1 & -.06 & $.37^{* *}$ & .07 & .08 & -.10 & .11 & $.18^{*}$ & $.19^{* *}$ & .04 & -.13 & 33.91 & 13.72 \\
\hline 2. Gender & .78 & .42 & .02 & 1 & .09 & $-.40^{* *}$ & $-.24^{* * *}$ & $-.16^{*}$ & -.09 & -.01 & -.13 & $-.20^{* *}$ & $-.19^{*}$ & .63 & .48 \\
\hline 3. Education & 4.43 & 1.32 & $.37^{* * *}$ & .01 & 1 & $-.15^{*}$ & .13 & -.01 & -.09 & .09 & .03 & .04 & -.09 & 4.03 & 1.30 \\
\hline 4. Survey completion day & 3.12 & 2.16 & $-.09^{*}$ & $-.13^{* *}$ & $-.10^{*}$ & 1 & $.17^{*}$ & .078 & $.28^{* *}$ & .12 & $.22^{* *}$ & $.19^{* *}$ & $.26^{* *}$ & 9.50 & 4.27 \\
\hline $\begin{array}{l}\text { 5. Communicating general } \\
\text { information (CGI) }\end{array}$ & 6.34 & 1.01 & .08 & $.10^{*}$ & $.10^{*}$ & .05 & 1 & $.52^{* *}$ & $.22^{* *}$ & $.16^{*}$ & $.35^{* *}$ & $.30^{* *}$ & .13 & 5.39 & 1.50 \\
\hline $\begin{array}{l}\text { 6. Communicating humoristic } \\
\text { information }(\mathrm{CHI})\end{array}$ & 4.60 & 2.12 & $-.11^{*}$ & $-.09^{*}$ & -.02 & -.00 & $.22^{* *}$ & 1 & $.18^{*}$ & .11 & .13 & $.16^{*}$ & .00 & 3.68 & 2.04 \\
\hline 7. Death anxiety (DA) & 2.76 & 1.10 & -.05 & $.10^{*}$ & .06 & .05 & $.13^{* *}$ & -.05 & 1 & $.49^{* *}$ & $.55^{* *}$ & $.37^{* * *}$ & $.30^{* *}$ & 2.96 & 1.04 \\
\hline 8. Death reflection (DR) & 3.72 & .55 & $.09^{*}$ & .03 & .02 & -.00 & $.11^{* * *}$ & -.04 & $.16^{* *}$ & 1 & $.26^{* *}$ & $.19^{* * *}$ & .05 & 3.36 & .75 \\
\hline 9. COVID-19 anxiety & 3.27 & .99 & .03 & $.18^{* *}$ & $.08^{*}$ & $.12^{* *}$ & $.15^{* *}$ & $-.11^{* *}$ & $.51^{* *}$ & $.10^{*}$ & 1 & $.60^{* *}$ & $.28^{* *}$ & 2.79 & 1.10 \\
\hline 10. COVID-19 negative mood & 2.51 & .65 & $-.17^{* *}$ & .06 & -.00 & $.10^{*}$ & $.12^{* * *}$ & -.02 & $.33^{* *}$ & -.04 & $.42^{* *}$ & 1 & $.27^{* *}$ & 2.69 & .88 \\
\hline 11. Social distance & 62.80 & 25.59 & -.01 & .08 & -.07 & .04 & .00 & $-.09^{*}$ & $.12^{* *}$ & .01 & $.18^{* * *}$ & $.17^{* *}$ & 1 & 88.80 & 17.30 \\
\hline
\end{tabular}

******Note. Correlation coefficients are presented in the table with the scores for the Kazakhstan sample above the diagonal and means and standard deviations presented in the last column; Gender was coded as a dummy variable with $1=$ females and $0=$ males; $\mathrm{RO}=\mathrm{Romania}$ and $\mathrm{KZ}=\mathrm{Kazakhstan}$; the effect size of a zero-order correlation is indicated by its absolute value (Cohen, 1992$) ; p<.05 ; p<.01 ; p<.001$;

We have used OLS regression analyses to test our hypotheses and we have combined these analyses with a bootstrapping approach to test the moderated mediation model using the macros and procedures described in Hayes (2012). In all regression analyses, we have used as controls all variables that could have influenced the independent, mediator and dependent variables stated in our hypotheses. Therefore, age, gender, education, country of origin and survey completion date were used as control variables. We first ran regression analyses to predict the two emotional dimensions related to COVID-19, namely anxiety and negative mood. In order to test hypotheses 1 to 6 , we have used a stepwise procedure and we have entered all control variables and main predictors (communicating general information about COVID-19, communicating humoristic communication about COVID-19, death anxiety and death reflection) in the first step (Model 1) of the regression analysis. The second step (Model 2) included the interaction terms between communicating general and humoristic information about COVID-19 as well as the interaction between death anxiety and death reflection. Before computing the cross-product terms, the variables were grand mean centered. The results of the regression analyses are presented in Table 2.

As indicated in Table 2 , death anxiety positively predicts COVID-19 anxiety $(\beta=.48, p<.001)$ as well as negative mood in relation to COVID-19 $(\beta=.32, p<.001)$, therefore hypotheses $1 \mathrm{a}$ and $1 \mathrm{~b}$ were fully supported. Moreover, death reflection negatively predicted negative $\operatorname{mood}(\beta=-.08$, $p=.048$ ) supporting Hypothesis $2 \mathrm{~b}$, yet its association with COVID-19 anxiety, although negative as predicted, is not statistically significant $(\beta=-.03, p=.84)$, therefore Hypothesis 2a was not supported. The interaction between death anxiety and death reflection is significant for COVID-
19 anxiety $(\beta=-.08, p=.01)$ as well as for negative mood $(\beta=-.12, p=.001)$. The significant interaction effect between death anxiety and death reflection on COVID-19 anxiety is depicted in Fig. 1 and the significant interaction effect on negative mood is depicted in Fig. 2. In both figures, the slope analysis and the conditional effects reported in Table 3 show that death reflection alleviates the positive association between death anxiety and both negative emotionality indices, therefore hypotheses $3 \mathrm{a}$ and $3 \mathrm{~b}$ were supported.

The effects of interpersonal communication were also aligned with the general hypotheses. Exchanging general COVID-19 information with close social contacts had a positive association with COVID-19 anxiety $(\beta=.15, p<.001)$ as well as with negative $\operatorname{mood}(\beta=.10, p=.03)$, therefore hypothesis $4 \mathrm{a}$ and $4 \mathrm{~b}$ were supported. Using humoristic communication in relation to COVID-19 predicted negatively and significantly COVID-19 anxiety $(\beta=-.09, p=.01)$, supporting Hypothesis $5 \mathrm{a}$ and a negative yet not significant association with negative mood $(\beta=-.01, p=.73)$, therefore Hypothesis $5 \mathrm{~b}$ received no support. The interaction between using the two types of information in communication was only significant for negative mood $(\beta=-.09, p=.02)$ and it was not significant for COVID-19 anxiety $(\beta=.01, p=.85)$. The significant interaction between communicating general COVID-19 information and the use of humoristic information is depicted in Fig. 3 and the conditional effects are presented in Table 4. As indicated by the slopes and the conditional effects, the use of humoristic information in relation to COVID-19 attenuates the positive association between exchanging general information and the negative mood in relation to COVID-19, therefore Hypothesis 6b was supported while Hypothesis 6a received no empirical support. 
Table 2 Results of the regression analyses

\begin{tabular}{|c|c|c|c|c|c|c|}
\hline \multirow[t]{2}{*}{ Variable } & \multicolumn{2}{|c|}{ COVID-19 anxiety } & \multicolumn{2}{|c|}{ COVID-19 negative mood } & \multicolumn{2}{|l|}{ Social distance } \\
\hline & Model 1 & Model 2 & Model 1 & Model 2 & Model 1 & Model 2 \\
\hline Constant & $2.03 * * *(.20)$ & $2.05 * * *(.20)$ & $2.71 * * *(.15)$ & $2.74 * * *(.15)$ & $79.99 * * *(5.82)$ & $72.30 * * *(6.52)$ \\
\hline Gender & $.21 * *(.08)$ & $.21 * *(.08)$ & $-.05(.06)$ & $-.03(.06)$ & $.81(2.07)$ & $1.21(2.07)$ \\
\hline Age & $.01^{\dagger}(.003)$ & $.01(.003)$ & $-.01 * *(.002)$ & $-.01 * *(.002)$ & $-.06(.08)$ & $-.02(.08)$ \\
\hline Education & $.02(.03)$ & $.02(.03)$ & $.02(.02)$ & $.02(.02)$ & $-1.30^{\dagger}(.71)$ & $-1.36^{\dagger}(.71)$ \\
\hline Survey completion day & $.04 * *(.01)$ & $.04 * *(.01)$ & $.02 *(.01)$ & $.02 *(.01)$ & $.50(.32)$ & $.47(.32)$ \\
\hline Country & $.68 * *(.11)$ & $.68 * * *(.11)$ & $-.07(.09)$ & $-.08(.08)$ & $-22.97 * * *(3.07)$ & $-22.01 * * *(3.08)$ \\
\hline Communicating general information (CGI) & $.13 * * *(.03)$ & $.13 * * *(.03)$ & $.09 * * *(.02)$ & $.06^{*}(.03)$ & $.37(.82)$ & $.17(.82)$ \\
\hline Communicating humoristic information (CHI) & $-.04 * *(.02)$ & $-.04 *(.02)$ & $-.01(.01)$ & $-.004(.01)$ & $-.89 *(.44)$ & $-.90 *(.44)$ \\
\hline Death anxiety (DA) & $.45 * * *(.03)$ & $.45 * * *(.03)$ & $.21 * * *(.02)$ & $.21 * * *(.02)$ & $1.37(.95)$ & $1.10(.95)$ \\
\hline Death reflection (DR) & $-.01(.05)$ & $-.05(.06)$ & $-.05(.04)$ & $-.09 *(.04)$ & $-.82(1.49)$ & $-.63(1.49)$ \\
\hline CGIxCHI & & $.003(.01)$ & & $-.02 *(.01)$ & & \\
\hline DAxDR & & $-.11 *(.04)$ & & $-.11 * *(.03)$ & & \\
\hline COVID-19 anxiety & & & & & $3.55 * *(1.03)$ & $2.50^{*}(1.1)$ \\
\hline COVID-19 negative mood & & & & & & $3.63 *(1.41)$ \\
\hline $\mathrm{N}$ & 736 & 736 & 736 & 736 & 736 & 736 \\
\hline $\mathrm{R}^{2}$ & 0.35 & .35 & .17 & 0.18 & .23 & .24 \\
\hline F statistic & $42.45 * * *$ & $3.06^{*}$ & $15.91 * * *$ & $8.06 * * *$ & $21.33 * * *$ & $6.65^{*}$ \\
\hline
\end{tabular}

$\dagger * * * * *$ Note. Unstandardized regression coefficients are presented in the table with standard errors in between brackets; Gender was coded as a dummy variable with $1=$ females and $0=$ males; Country was coded as a dummy variable with $\mathrm{RO}=1$ and $\mathrm{KZ}=0 ; p<0.10 ; \mathrm{p}<.05 ; \mathrm{p}<.01 ; \mathrm{p}<.001$

Social distance towards people infected with COVID-19 was positively predicted by COVID-19 anxiety $(\beta=.10, p=.02)$ as specified in Hypothesis 7 as well as by negative $\operatorname{mood}(\beta=.10$, $p=.01$ ) in relation to COVID-19 as specified in Hypothesis 8, therefore the two hypotheses were supported by the data. In order to test the mediation hypotheses, we have used the PROCESS macro (Hayes, 2012) with model 7 that tests the moderated mediation separately for COVID-19 anxiety as well as negative mood. The indirect association between death anxiety and social distance through COVID-19 anxiety was significant at all levels
Fig. 1 The interaction between death anxiety and death reflection on COVID-19 anxiety

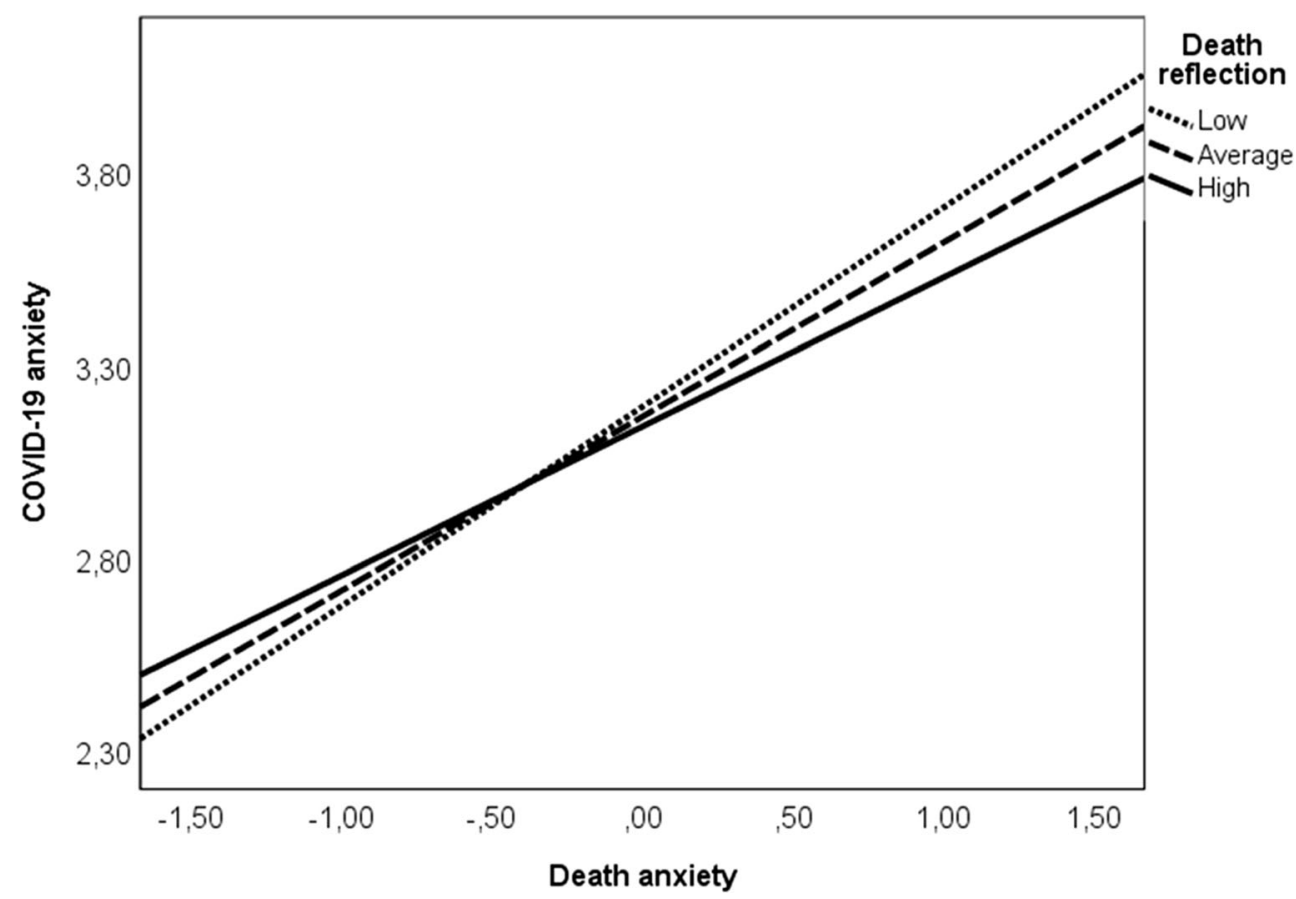


Fig. 2 The interaction between death anxiety and death reflection on negative mood in relation to COVID-19

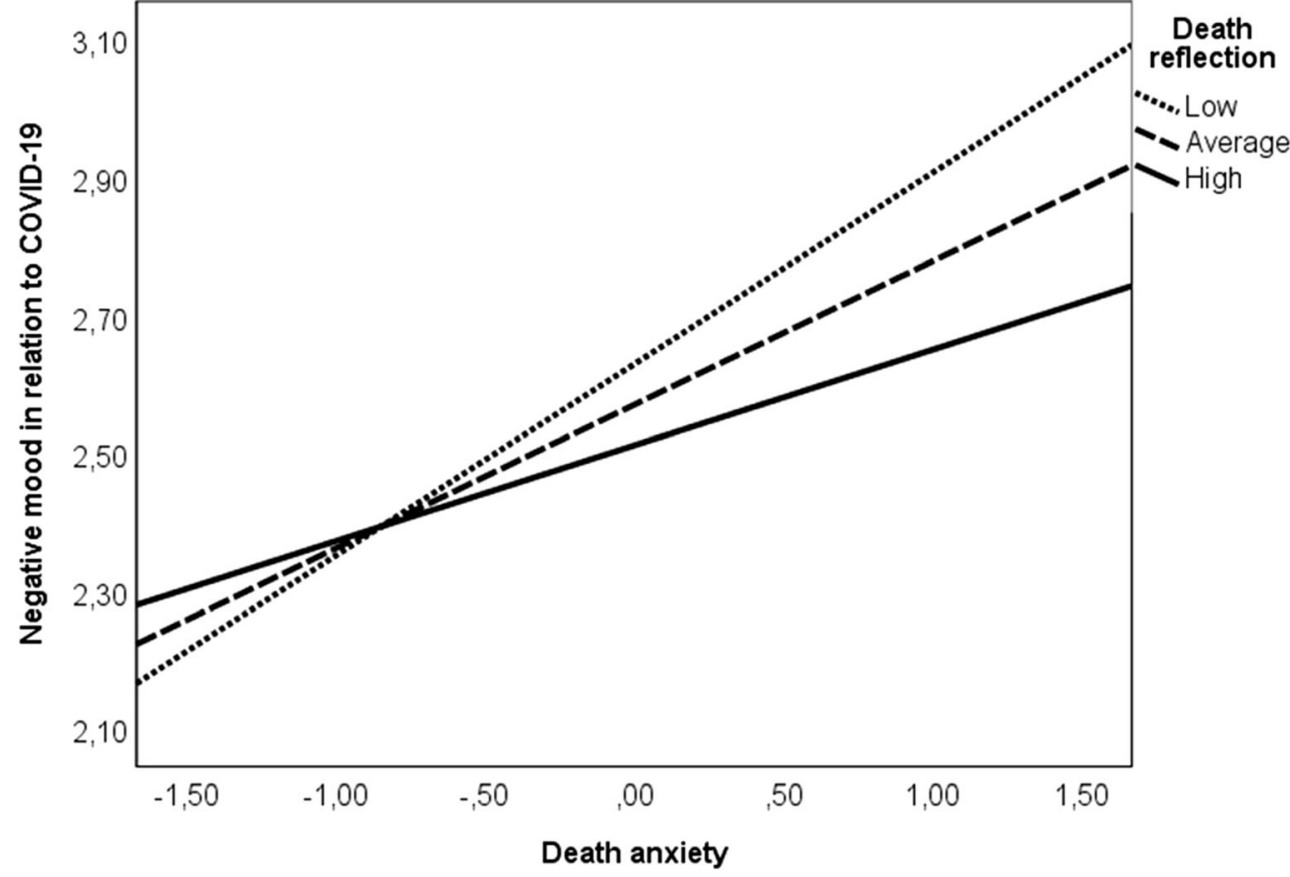

of death reflection as indicated in Table 5 that presents the indirect effects of death anxiety under different levels of death reflection. The indirect effect of death anxiety on social distance as mediated by negative mood in relation to COVID-19 was only significant when death reflection was low or average showing a significant moderated mediation effect $(\mathrm{B}=-.40, \mathrm{SE}=.21$, 95\%CI [-.89;-.07]). These results support Hypothesis 9 stating that the association between death anxiety and social distance is mediated by anxiety as a state and negative mood in relation to COVID-19.

The effect of communicating general COVID-19 information on social distance was mediated by COVID-19 anxiety irrespective of the extent to which humor was used in communication as shown in Table 6 . The mediating role of negative mood was, however, only significant when the use of humor in communication is low or average, showing a significant moderated mediation $(\mathrm{B}=-.08, \mathrm{SE}=.05,95 \% \mathrm{CI}$ $[-.20 ;-.003])$ in the case of negative mood. Overall, these results fully support Hypothesis 10 .

The mediation models tested in our paper were derived from theoretical arguments that anxiety as a trait predicts

Table 3 Conditional effects of death anxiety on COVID-19 anxiety and negative mood in relation to COVID-19

\begin{tabular}{llllll}
\hline \multirow{2}{*}{ Death reflection } & \multicolumn{2}{l}{ COVID-19 anxiety } & & \multicolumn{2}{l}{ Negative mood } \\
\cline { 2 - 3 } \cline { 6 - 7 } \cline { 6 - 7 } & Effect (SE) & $95 \%$ CI & & Effect (SE) & $95 \%$ CI \\
\hline Low & $.52(.04)$ & {$[.44 ; .60]$} & & $.28(.03)$ & {$[.21 ; .34]$} \\
Average & $.45(.03)$ & {$[.39 ; .51]$} & & $.21(.02)$ & {$[.16 ; .25]$} \\
High & $.39(.04)$ & {$[.31 ; .46]$} & & $.14(.03)$ & {$[.08 ; .20]$} \\
\hline
\end{tabular}

anxiety as a state (Fleeson, 2001; Schmukle \& Egloff, 2004) and communicating information about the threatening nature of COVID-19 triggers anxiety and negative mood (Garfin et al., 2020; Gao et al., 2020). However, our data is crosssectional and we cannot make causal claims based on the analyses presented above. Experimental research is the only viable way of clarifying causal claims and although testing alternative mediation models will not allow us to refute reverse causation, we have decided to test a reverse causation model with social distance predicting COVID-19 anxiety and negative mood, which in turn predict death anxiety and use of COVID-19 information in communication (all other variables reported in previous analyses were used as covariates). We have used the PROCESS macro (Hayes, 2012) with model 4 to simultaneously estimate the mediating role of COVID-19 anxiety and negative mood and we have tested both the originally hypothesized models as well as the alternative mediation models with the dependent and independent variables swapped. The results of these reverse causation tests are presented in Table 7. As indicated in Table 7 the hypothesized model was fully supported by the data, while for the alternative mediation models all indirect effects were virtually zero.

Next to the hypothesized effects, we report several significant relations between the control variables and the dependent variables considered in the study. Gender had a positive association with COVID-19 anxiety ( $\beta=.09, p=.004)$ in that females reported more anxiety than males did in relation to COVID-19. Age had a negative and significant association with negative mood in relation to COVID-19 $(\beta=-.12, p=.002)$ showing that older respondents reported a less negative mood towards COVID-19 than younger respondents did. Survey completion 
Fig. 3 The interaction between communicating general information about COVID-19 and communicating humoristic information on negative mood in relation to COVID-19

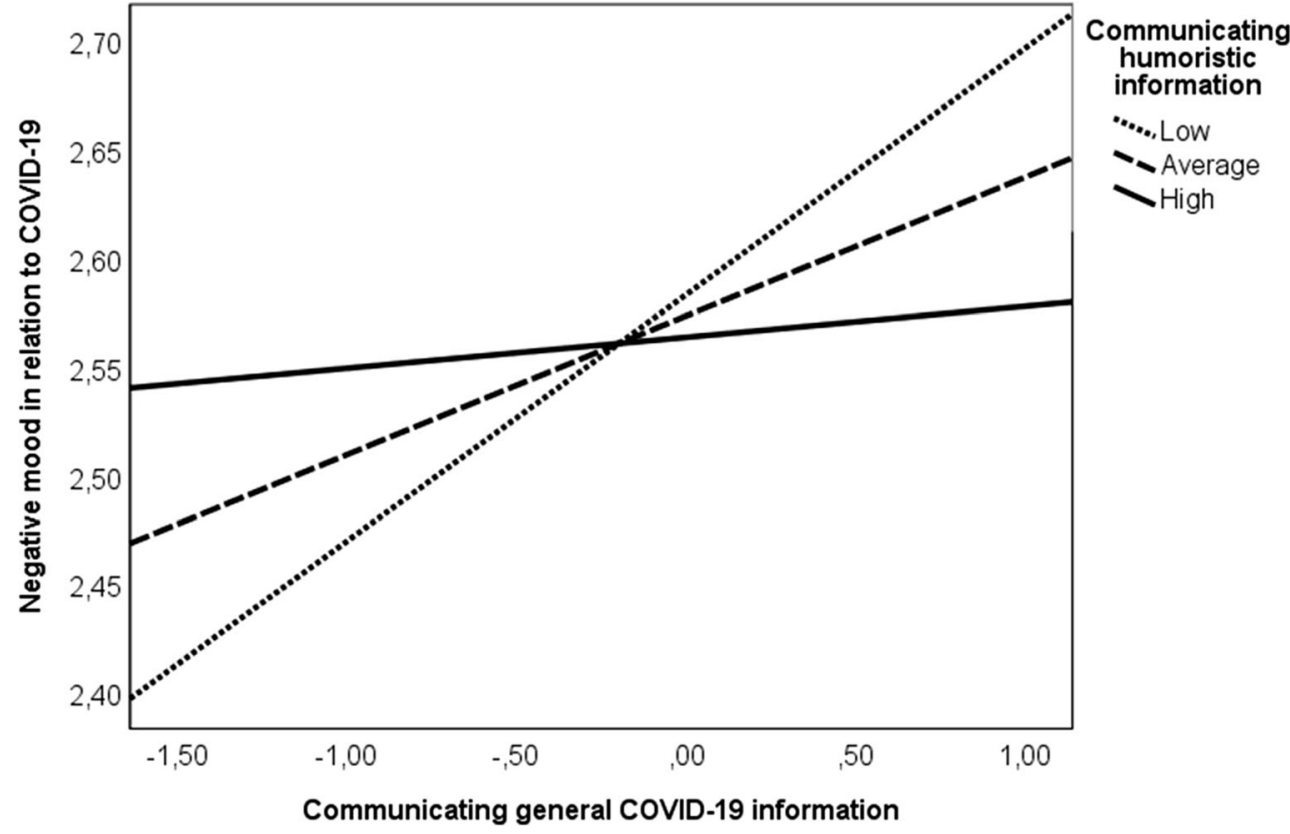

day had a positive association with COVID-19 anxiety $(\beta=.15$, $p=.001)$, with negative mood $(\beta=.12, p=.02)$ but not with the social distance in relation to people infected with COVID-19 ( $\beta=.07, p=.15$ ) showing that although negativity in relation to COVID-19 increased with time lapse, the discriminative tendencies towards people with COVID-19 did not follow a similar trend. Finally, the country of origin had a significant and positive association with COVID-19 anxiety $(\beta=.28, p<.001)$ with respondents that filled out the survey in Romanian reporting more anxiety than respondents that filled out the survey in Russian. Participants in Kazakhstan though, report significantly higher scores for social distance towards people infected with COVID-19 than Romanian participants did $(\beta=-.36, p<.001)$.

\section{Discussion}

Our study explored some of the emotional correlates of the COVID-19 pandemic. One of the most important global stressors of the last decades, COVID-19 is on the first page of the media reports, on top of the political agendas and occupies a

Table 4 Conditional effects of communicating general information and communicating humoristic information on negative mood in relation to COVID-19

\begin{tabular}{|c|c|c|}
\hline \multirow{2}{*}{ Communicating humoristic information } & \multicolumn{2}{|c|}{ Negative mood } \\
\hline & Effect (SE) & $95 \% \mathrm{CI}$ \\
\hline Low & $.11(.02)$ & {$[.07 ; .16]$} \\
\hline Average & $.06(.03)$ & {$[.01 ; .12]$} \\
\hline High & $.01(.04)$ & {$[-.07 ; .10]$} \\
\hline
\end{tabular}

central place in interpersonal communication and information exchanges in society. Our results show that the extent to which people talk about COVID-19 is positively associated with their reported anxiety and negative mood in relation to COVID-19. The use of humoristic messages in communication however, reduces anxiety and alleviates the positive association between general COVID-19 communication and negative mood associated with COVID-19. Our study extends the research on the beneficial role of using humor in stressful and health-related contexts (Ford et al., 2012; Schneider et al., 2018) and shows that using humor in interpersonal communication in relation to COVID-19 reduces the negativity of the emotional experiences related to the pandemic. Simply put, our results show that the use of humor in COVID-19 communication serves two functions: as anxiety buffer (reduces COVID-19 anxiety directly) and as mood fixer (attenuates the positive effect of general COVID-19 communication on negative mood). Previous research has explored some of the potential mechanisms that explain these beneficial effects, such as the beneficial effects of using humor for the cardiovascular and immune systems, its social capital benefits, or its distractive functions from the traumatic nature of various stressors (Curran et al., 2021; Nabi, 2016). Such mechanisms cannot be inferred from the results reported in our study and future research could explore the extent to which they actually play a role in explaining the buffering role of humor in relation to emotional reactions to infectious diseases.

We build on and extend the insights from the TMT to show that death anxiety as a trait is a core predictor of COVID-19 anxiety as a state (associated with the outbreak of the pandemic) and we also show that death reflection plays an alleviating role in this association. These results go beyond the state-trait discussion in anxiety research by showing that cognitive 
Table 5 Conditional indirect effects of death anxiety depending on the levels of death reflection on COVID-19 anxiety and negative mood

\begin{tabular}{|c|c|c|c|c|}
\hline \multirow[t]{2}{*}{ Death reflection } & \multicolumn{2}{|c|}{$\begin{array}{l}\text { Mediated by COVID-19 } \\
\text { anxiety }\end{array}$} & \multicolumn{2}{|c|}{$\begin{array}{l}\text { Mediated by negative } \\
\text { mood in relation to } \\
\text { COVID-19 }\end{array}$} \\
\hline & Effect (SE) & $95 \% \mathrm{CI}$ & Effect (SE) & $95 \% \mathrm{CI}$ \\
\hline Low & $1.28(.61)$ & {$[.16 ; 2.55]$} & $1.00(.41)$ & {$[.29 ; 1.89]$} \\
\hline Average & $1.12(.52)$ & {$[.14 ; 2.18]$} & $.75(.31)$ & {$[.21 ; 1.45]$} \\
\hline High & $.96(.45)$ & {$[.12 ; 1.88]$} & $.50(.24)$ & {$[.11 ; 1.04]$} \\
\hline Overall index of moderated, moderated mediation & $-.26(.19)$ & {$[-.70 ; .001]$} & $-.40(.21)$ & {$[-.89 ;-.07]$} \\
\hline
\end{tabular}

reflection in relation to death buffers the translation of anxiety as a trait in a specific anxiety state triggered by the COVID-19 pandemic. Our results build on recent evidence on the role of affect in explaining the mortality salience effects (Lambert et al., 2014) and show that the negative mood associated with COVID-19 explains the association between COVID-19 anxiety and discrimination of infected people. In other words, in the naturalistic setting in which we conducted our research, namely the outbreak of a life-threatening pandemic, the negative mood and anxiety triggered by the pandemic explains the association between death anxiety and discrimination of those infected with COVID-19. Next to the negative health consequences associated with the disease, people that suffered from COVID-19 can suffer additional stress associated with the stigmatization and marginalization with potentially lasting interpersonal problems and further isolation.

An important result concerns the negative association between the use of humor in communication and social distance. The use of humor is more than just a "mood fixer" in the context of the COVID-19 pandemic, it is a buffer against anxiety related to the virus and ultimately a protective factor against discriminating those who were infected. Such insights contribute to the growing body of evidence concerning the beneficial effects of humor for health (Curran et al., 2008) and work-related outcomes (Romero \& Cruthirds, 2006). As previous research reported a positive and significant correlation between COVID-19 anxiety and passive suicidal ideation (Lee, 2020) it becomes important to develop a better understanding of buffers (including humor) against COVID-19 anxiety. Furthermore, research could explore the differences of using different types of humor in relation to the pandemic and how, for example, using aggressive versus affiliative types of humor may contextualize better the association between the use of humor and discrimination.

As mentioned above, Romanian participants report higher COVID-19 related anxiety than the respondents who filled out the survey in Kazakhstan. A reasonable explanation is that, despite almost the same measures taken at the same time (quarantines, entry restrictions, state of emergency since March 16, 2020) by the two countries, the number of COVID-19 cases at the time of the survey was higher in Romania than in Kazakhstan. We therefore believe that the higher epidemiological impact of COVID-19 in Romania, at the time of the study explains the higher scores for COVID-19 anxiety in the Romanian sample. Mass media in Romania often portrayed the pandemic as the result of the free travel and the inflow of Romanian citizens from European countries with a higher number of cases. In Kazakhstan, the geographical proximity with China was portrayed as the main source of the pandemic, yet the absence of visa-free agreements between the two countries may have limited respondents' anxiety in relation to COVID-19.

What was surprising is that the lower level of the COVID-19 anxiety reported in the Kazakh sample is combined with significantly higher scores for social distance towards people infected with COVID-19 than in the Romanian sample. In line with Hypothesis 7 a low level COVID-19 anxiety should be associated with a smaller social distance towards people infected with COVID-19. A possible explanation for this difference between the two countries could be the "personification" of the potential carriers of COVID-19. Despite the fact that for both countries the epidemic was portrayed as a threat coming from outside (from
Table 6 Conditional indirect effects of communicating general information and communicating humoristic information depending on communicating humoristic information on negative mood in relation to COVID-19 and negative mood

\begin{tabular}{llllll}
\hline $\begin{array}{l}\text { Communicating humoristic information } \\
\text { in relation to COVID-19 }\end{array}$ & \multicolumn{2}{l}{$\begin{array}{l}\text { Mediated by COVID-19 } \\
\text { anxiety }\end{array}$} & & \multicolumn{2}{l}{$\begin{array}{l}\text { Mediated by negative mood } \\
\text { in relation to COVID-19 }\end{array}$} \\
\cline { 2 - 3 } & Effect (SE) & $95 \%$ CI & & Effect (SE) & $95 \%$ CI \\
\hline Low & $.35(.17)$ & {$[.06 ; .73]$} & & $.40(.20)$ & {$[.08 ; .86]$} \\
Average & $.36(.18)$ & {$[.06 ; .76]$} & & $.23(.15)$ & {$[.01 ; .56]$} \\
High & $.37(.22)$ & {$[.03 ; .87]$} & & $.05(.17)$ & {$[-.28 ; .44]$} \\
Overall index of moderated, moderated mediation & $.005(.04)$ & {$[-.08 ; .09]$} & $-.08(.05)$ & {$[-.20 ;-.003]$}
\end{tabular}


Table 7 Results of the alternative mediation models test (results of the simple mediation with no interactions included)

\begin{tabular}{|c|c|c|c|c|}
\hline \multirow[t]{2}{*}{ Model $/$ mediator } & \multicolumn{2}{|c|}{ COVID-19 Anxiety } & \multicolumn{2}{|c|}{ Negative mood } \\
\hline & Effect (SE) & $95 \% \mathrm{CI}$ & Effect (SE) & $95 \% \mathrm{CI}$ \\
\hline $\mathrm{DA} \rightarrow \mathrm{COVID} 19 \mathrm{ANX} / \mathrm{NM} \rightarrow \mathrm{SD}$ (Hypothesized model) & $1.12(.52)$ & {$[.13 ; 2.14]$} & $.73(.31)$ & {$[.15 ; 1.38]$} \\
\hline $\mathrm{SD} \rightarrow \mathrm{COVID} 19 \mathrm{ANX} / \mathrm{NM} \rightarrow \mathrm{DA}$ (Alternative model) & $.00(.00)$ & {$[.00 ; .00]$} & $.00(.00)$ & {$[.00 ; .00]$} \\
\hline CGI $\rightarrow$ COVID19ANX/NM $\rightarrow$ SD (Hypothesized model) & $.33(.17)$ & {$[.03 ; 70]$} & $.34(.16)$ & {$[.06 ; .69]$} \\
\hline $\mathrm{SD} \rightarrow$ COVID19ANX/NM $\rightarrow$ CGI (Alternative model) & $.00(.00)$ & {$[.00 ; .00]$} & $.00(.00)$ & {$[.00 ; .00]$} \\
\hline
\end{tabular}

Note: DA death anxiety, COVID19ANX COVID-19 anxiety, NM negative mood, SD social distance, CGI communicate general information about COVID-19

abroad), the carriers were in-group nationals for Romania and out-group nationals for Kazakhstan. Romanian nationals traveling from Italy or Spain were presented as the main source of COVID-19 infections in Romania, while for Kazakhstan the source was depicted as being Chinese visitors. This countrylevel difference on social distance towards people infected with COVID-19 may therefore confound public messaging related to the source of the virus from two overlapping different categories, an in-group for Romania and an out-group for Kazakhstan. As previous research reported a positive association between COVID-19 anxiety and avoidance of Chinese products or foods (Lee, 2020) and at a global scale the COVID-19 pandemic was often tied to a xenophobic discourse in political communication (Clissold et al., 2020), more cross-cultural research is needed to tap into differences in intergroup relations and conflict stemming from COVID-19 public communication.

Our results also showed that females reported higher COVID anxiety than males did, yet our results did not reveal significant gender differences in negative mood. This pattern of result is aligned with meta-analytic evidence showing that females tend to score higher in anxiety as a trait (Feingold, 1994). This result is likely to be explained by the fact that females may perceive themselves as being less capable of coping with threatening situations and imminent stressors than males do (McLean \& Anderson, 2009). Moreover, the negative association between age and negative mood could be explained by the fact that older adults tend to be more susceptible to positivity bias (tendency to focus and process in a preferential manner positive information cues rather than negative ones) than younger adults are (Reed et al., 2014).

\section{Limitations}

Our study has several limitations. First, our study is cross sectional, therefore no causal claims can be made based on our results. We have tested the mediation relations following the causal links derived from our theoretical analysis and although our alternative model testing supports the hypothesized model rather than the alternative one (in which we swapped the independent and dependent variables), no causal claims can be derived from our results. Second, data for all variables included in our study were self-reported, therefore our results are susceptible to the common method bias and should be interpreted with caution. In order to alleviate these concerns, we have used different scale anchors (Podsakoff et al., 2011) and because variables included in our study are difficult to evaluate from different sources, future longitudinal research could alleviate the concern related to the common method bias. Moreover, as shown in simulation studies (Evans, 1985), when testing interactions, the common method bias is less problematic and the estimated interaction effects are not very likely to be overestimated as a result of common method bias (Siemsen et al., 2010). Third, COVID-19 communication and negative mood were evaluated using a single item and this could have affected the reliability of the measures. When items are phrased in non-ambiguous way and reflect concepts common to participants' daily experiences, single-item measures can be appropriated (Wanous, \& Reichers, 1996; Wanous et al., 1997) and because we have explained the meaning of mood in the item description, and we have specified unambiguous anchors for the frequency of COVID-19 communication, we hope we have cleared the conceptual ambiguity and obtained rather accurate indicators of these variables. Future research, however, could explore different aspects of emotions and affect related to the discrimination of people suffering from infectious diseases. Finally, our study aimed to explore the antecedents and social consequences of negative emotionality related to COVID-19 at the very beginning of the pandemic, therefore we have used a convenience sampling approach, therefore we cannot claim that our findings are representative for the two populations.

\section{Practical Implications}

Our results have some important practical implications. First, we point out that the COVID-19 infection can generate additional harm through the social consequences tied to discriminatory tendencies and social isolation of those who were infected. Of course, one could say that social distance towards the infected people is also a protective strategy (in the public communication it is stated that physical distance is a key preventing mechanism for the further spread of the virus), yet in our study we have 
evaluated social distance as an index of prejudice. Public messages have emphasized the term "social distancing" from the onset of the pandemic-related communication. The emphasis on "social" in this context is somehow misleading because in such crisis situations, social closeness can be an important protective factor (Clissold et al., 2020). Our index of social distance captures really the prejudicial distancing from people infected with COVID-19. Translating the seven items used in the scale to evaluate social distance into physical distance, only the first item ("to accept someone to close kinship by marriage") would actually overlap with the physical distancing that could, in principle lead to a direct transmission of the virus. As such, we believe that our social distance is not a mere reflection of the persuasive "Keep the distance" messages and the scale captures prejudice towards people infected with COVID-19. We believe that the additional stress generated by discrimination, marginalization and social isolation of those who were infected should be systematically addressed through supportive healthcare practices. Moreover, in line with previous calls (Clissold et al., 2020) we plea for raising awareness in society as a whole concerning the disruptive effects of discriminatory tendencies potentially targeting people that were infected with COVID-19.

Second, our results could contribute to prevent more general intergroup tensions associated with the pandemic. Historic evidence suggests that the socially shared meaning about pandemics or the pandemic's identity often reflects underlying prejudice and can increase social segregation and further marginalization of minority groups (Clissold et al., 2020). Given the fact that the COVID-19 pandemic is often labeled in mass-media and political messages as "coming from abroad", such social distancing from people infected with corona may overlap with other discriminatory practices and (re)fuel intergroup tensions. As the political leaders are the key actors that initiate the shared view on pandemic's identity, we plea for moderation and wisdom in shaping public communication in relation to the pandemic. Political actors are not the only ones who shape the identity of the pandemic in the social discourse. The use of social media plays an important role in how such an identity is created and maintained, therefore we also plea for raising wide public awareness concerning the essential role of social cohesion as one of the key ingredients of battling the pandemic.

\section{Compliance with Ethical Standards}

Conflict of Interests The authors have no conflict of interests to declare.

Informed Consent All participants were informed of the aim of the study and gave their informed consent, the study complies with the 1964 Declaration of Helsinki and its later addenda, and the survey on which our study is based was approved by the Ethical Review Board of the Babeș-Bolyai University, Cluj-Napoca Romania. The datasets generated and analyzed during the current study are available from the corresponding author on reasonable request.

\section{Appendix}

Table 8 Overview of the hypotheses tested in the study

\begin{tabular}{|c|c|}
\hline Hypotheses & Status \\
\hline $\begin{array}{l}\text { H1: Death anxiety fosters COVID-19 anxiety state (H1a) and negative mood in relation to } \\
\text { COVID-19 (H1b) }\end{array}$ & $\begin{array}{l}\text { H1a-supported } \\
\text { H1b-supported }\end{array}$ \\
\hline $\begin{array}{l}\text { H2: Death reflection reduces COVID-19 anxiety state (H2a) and the negative mood in relation to } \\
\text { COVID-19 (H2b) }\end{array}$ & $\begin{array}{l}\text { H2a-not } \\
\text { supported } \\
\text { H2b-supported }\end{array}$ \\
\hline $\begin{array}{l}\text { H3: Death reflection reduces the positive association between death anxiety and COVID-19 anxiety } \\
\text { (H3a) and negative mood (H3b) }\end{array}$ & $\begin{array}{l}\text { H3a-supported } \\
\text { H3b-supported }\end{array}$ \\
\hline $\begin{array}{l}\text { H4: The use of general information concerning COVID-19 in interpersonal communication is pos- } \\
\text { itively associated with COVID-19 anxiety (H4a) and negative mood (H4b) }\end{array}$ & $\begin{array}{l}\text { H4a-supported } \\
\text { H4b-supported }\end{array}$ \\
\hline $\begin{array}{l}\text { H5: The use of humoristic information about COVID-19 in interpersonal communication is nega- } \\
\text { tively associated with COVID-19 anxiety (H5a) and negative mood (H5b) }\end{array}$ & $\begin{array}{l}\text { H5a-supported } \\
\text { H5b-not } \\
\text { supported }\end{array}$ \\
\hline $\begin{array}{l}\text { H6: The use of humoristic information about COVID-19 in interpersonal communication alleviates } \\
\text { the positive association between the use of general information and COVID-19 anxiety (H6a) and } \\
\text { negative mood (H6b) }\end{array}$ & $\begin{array}{l}\text { H6a-supported } \\
\text { H6b-not } \\
\text { supported }\end{array}$ \\
\hline H7: COVID-19 anxiety positively predicts social distance towards people infected with COVID-19 & H7-supported \\
\hline $\begin{array}{l}\text { H8: Negative mood in relation to COVID-19 has a positive association with social distance towards } \\
\text { people infected with COVID-19 }\end{array}$ & H8-supported \\
\hline $\begin{array}{l}\text { H9: COVID-19 anxiety and negative mood mediate the association between death anxiety and social } \\
\text { distance towards people infected with COVID-19 }\end{array}$ & H9-supported \\
\hline H10: COVID-19 anxiety and negative mood in relation to COVID-19 mediate the association & H10-supported \\
\hline
\end{tabular}




\section{References}

Belmi, P., \& Pfeffer, J. (2016). Power and death: Mortality salience increases power seeking while feeling powerful reduces death anxiety. Journal of Applied Psychology, 101(5), 702-720.

Bhattacharyya, P., Jena, L. K., \& Pradhan, S. (2019). Resilience as a mediator between workplace humour and well-being at work: An enquiry on the healthcare professionals. Journal of Health Management, 21(1), 160-176.

Broudy, R., Brondolo, E., Coakley, V., Brady, N., Cassells, A., Tobin, J. N., \& Sweeney, M. (2007). Perceived ethnic discrimination in relation to daily moods and negative social interactions. Journal of Behavioral Medicine, 30(1), 31-43.

Cao, W., Fang, Z., Hou, G., Han, M., Xu, X., Dong, J., \& Zheng, J. (2020). The psychological impact of the COVID-19 epidemic on college students in China. Psychiatry Research, 287, 112934.

Cheung, F., \& Lucas, R. E. (2014). Assessing the validity of single-item life satisfaction measures: Results from three large samples. Quality of Life Research, 23(10), 2809-2818.

Clissold, E., Nylander, D., Watson, C., \& Ventriglio, A. (2020). Pandemics and prejudice. International Journal of Social Psychiatry, 66, 421-423.

Cohen, J. (1992). A power primer. Psychological Bulletin, 112(1), 155159

Curran, T., Janovecm A. \& Olsen, K. (2021) Making others laugh is the best medicine: humor orientation, health outcomes, and the moderating role of cognitive flexibility. Health Communication, 36(4), 468-475. https://doi.org/10.1080/10410236.2019.1700438.

Curșeu, P. L., Stoop, R., \& Schalk, R. (2007). Prejudice toward immigrant workers among Dutch employees: Integrated threat theory revisited. European Journal of Social Psychology, 37(1), 125-140.

Evans, M. G. (1985). A Monte Carlo study of the effects of correlated method variance in moderated multiple regression analysis. Organizational Behavior and Human Decision Processes, 36, 305-323.

Feingold, A. (1994). Gender differences in personality: A meta-analysis. Psychological Bulletin, 116(3), 429-456.

Fleeson, W. (2001). Toward a structure-and process-integrated view of personality: Traits as density distributions of states. Journal of Personality and Social Psychology, 80(6), 1011-1027.

Florian, V., \& Mikulincer, M. (1997). Fear of death and the judgment of social transgressions: A multidimensional test of terror management theory. Journal of Personality and Social Psychology, 73(2), 369380.

Ford, T. E., Ford, B. L., Boxer, C. F., \& Armstrong, J. (2012). Effect of humor on state anxiety and math performance. Humor, 25(1), 5974.

Gao, J., Zheng, P., Jia, Y., Chen, H., Mao, Y., Chen, S., Wang, Y., Fu, H., \& Dai, J. (2020). Mental health problems and social media exposure during COVID-19 outbreak. PLoS One, 15(4), e0231924. https:// doi.org/10.1371/journal.pone.0231924.

Garfin, D. R., Silver, R. C., \& Holman, E. A. (2020). The novel coronavirus (COVID-2019) outbreak: Amplification of public health consequences by media exposure. Health Psychology, 39, 355-357.

Greenberg, J., \& Kosloff, S. (2008). Terror management theory: Implications for understanding prejudice, stereotyping, intergroup conflict, and political attitudes. Social and Personality Psychology Compass, 2(5), 1881-1894.

Greenberg, J., Pyszczynski, T., Solomon, S., Rosenblatt, A., Veeder, M., Kirkland, S., \& Lyon, D. (1990). Evidence for terror management theory II: The effects of mortality salience on reactions to those who threaten or bolster the cultural worldview. Journal of Personality and Social Psychology, 58(2), 308-318.

Harmon-Jones, E., Simon, L., Greenberg, J., Pyszczynski, T., Solomon, S., \& McGregor, H. (1997). Terror management theory and self- esteem: Evidence that increased self-esteem reduced mortality salience effects. Journal of Personality and Social Psychology, 72(1), 24-36.

Hayes, A. F. (2012). PROCESS: A versatile computational tool for observed variable mediation, moderation, and conditional process modeling [White paper]. Retrieved from http://www.afhayes.com/ public/process2012.pdf

Hayes, A. F., \& Coutts, J. J. (2020). Use omega rather than Cronbach's alpha for estimating reliability. But $\cdots$. Communication Methods and Measures, 14, 1-24.

Kirkman, B. L., \& Chen, G. (2011). Maximizing your data or data slicing? Recommendations for managing multiple submissions from the same dataset. Management and Organization Review, 7(3), 433446.

Lambert, A. J., Eadeh, F. R., Peak, S. A., Scherer, L. D., Schott, J. P., \& Slochower, J. M. (2014). Toward a greater understanding of the emotional dynamics of the mortality salience manipulation: Revisiting the "affect-free" claim of terror management research. Journal of Personality and Social Psychology, 106(5), 655-678.

Lazarus, R. S. (1991). Emotion and adaptation. Oxford: Oxford University Press.

Lee, S. A. (2020). Coronavirus anxiety scale: A brief mental health screener for COVID-19 related anxiety. Death Studies, 44(7), 393-401.

Li, S., Wang, Y., Xue, J., Zhao, N., \& Zhu, T. (2020). The impact of COVID-19 epidemic declaration on psychological consequences: A study on active Weibo users. International Journal of Environmental Research and Public Health, 17(6), 2032.

Lynch, O. H. (2002). Humorous communication: Finding a place for humor in communication research. Communication Theory, 12(4), 423-445.

Mather, D. M., Jones, S. W., \& Moats, S. (2017). Improving upon Bogardus: Creating a more sensitive and dynamic social distance scale. Survey Practice, 10(4), 1-10.

McLean, C. P., \& Anderson, E. R. (2009). Brave men and timid women? A review of the gender differences in fear and anxiety. Clinical Psychology Review, 29(6), 496-505.

Nabi, R. L. (2016). Laughing in the face of fear (of disease detection): Using humor to promote cancer self-examination behavior. Health Communication, 31(7), 873-883.

Pettigrew, C. G., \& Dawson, J. G. (1979). Death anxiety: "State" or "trait"? Journal of Clinical Psychology, 35(1), 154-158.

Podsakoff, P. M., MacKenzie, S. B., \& Podsakoff, N. P. (2011). Sources of method bias in social science research and recommendations on how to control it. Annual Review of Psychology, 63, 1-31. https:// doi.org/10.1146/annurev-psych-120710-100452.

Pyszczynski, T., Greenberg, J., \& Solomon, S. (1999). A dual-process model of defense against conscious and unconscious death-related thoughts: An extension of terror management theory. Psychological Review, 106(4), 835-845.

Randler, C., Wüst-Ackermann, P., \& Demirhan, E. (2016). Humor reduces anxiety and disgust in anticipation of an educational dissection in teacher students. International Journal of Environmental and Science Education, 11(4), 421-432.

Reed, A. E., Chan, L., \& Mikels, J. A. (2014). Meta-analysis of the agerelated positivity effect: Age differences in preferences for positive over negative information. Psychology and Aging, 29(1), 1-15.

Romero, E. J., \& Cruthirds, K. W. (2006). The use of humor in the workplace. Academy of Management Perspectives, 20(2), 58-69.

Schmukle, S. C., \& Egloff, B. (2004). Does the implicit association test for assessing anxiety measure trait and state variance? European Journal of Personality, 18(6), 483-494.

Schneider, M., Voracek, M., \& Tran, U. S. (2018). "A joke a day keeps the doctor away?" meta-analytical evidence of differential associations of habitual humor styles with mental health. Scandinavian Journal of Psychology, 59(3), 289-300. 
Schwarz, N., \& Clore, G. L. (2003). Mood as information: 20 years later. Psychological Inquiry, 14(3-4), 296-303.

Sechrist, G. B., Swim, J. K., \& Mark, M. M. (2003). Mood as information in making attributions to discrimination. Personality and Social Psychology Bulletin, 29(4), 524-531.

Siemsen, E., Roth, A., \& Oliveira, P. (2010). Common method bias in regression models with linear, quadratic, and interaction effects. Organizational Research Methods, 13(3), 456-476.

Sliter, M. T., Sinclair, R. R., Yuan, Z., \& Mohr, C. D. (2014). Don't fear the reaper: Trait death anxiety, mortality salience, and occupational health. Journal of Applied Psychology, 99(4), 759-769.

Solomon, S., Greenberg, J., \& Pyszczynski, T. (1991). A terror management theory of social behavior: The psychological functions of selfesteem and cultural worldviews. In M. P. Zanna (Ed.), Advances in experimental social psychology (Vol. 24, pp. 91-159). San Diego: Academic Press.

Sorokowski, P., Groyecka, A., Kowal, M., Sorokowska, A., Białek, M., Lebuda, I., Zdybek, P., \& Karwowski, M. (2020). Can information about pandemics increase negative attitudes toward foreign groups? A case of COVID-19 outbreak. Sustainability, 12, 4912. https://doi. org/10.3390/su12124912.
Spielberger, C. D., \& Reheiser, E. C. (2009). Assessment of emotions: Anxiety, anger, depression, and curiosity. Applied Psychology: Health and Well-Being, 1(3), 271-302.

Wang, C., Pan, R., Wan, X., Tan, Y., Xu, L., Ho, C. S., \& Ho, R. C. (2020). Immediate psychological responses and associated factors during the initial stage of the 2019 coronavirus disease (COVID-19) epidemic among the general population in China. International Journal of Environmental Research and Public Health, 17(5), 1729.

Wanous, J. P., \& Reichers, A. E. (1996). Estimating the reliability of a single-item measure. Psychological Reports, 78(2), 631-634.

Wanous, J. P., Reichers, A. E., \& Hudy, M. J. (1997). Overall job satisfaction: How good are single-item measures? Journal of Applied Psychology, 82(2), 247-252.

Wark, C., \& Galliher, J. F. (2007). Emory Bogardus and the origins of the social distance scale. The American Sociologist, 38(4), 383-395.

Yuan, Z., Baranik, L. E., Sinclair, R. R., Sliter, M. T., Rand, K. L., \& Salyers, M. P. (2019). Memento Mori: The development and validation of the death reflection scale. Journal of Organizational Behavior, 40(4), 417-433.

Publisher's Note Springer Nature remains neutral with regard to jurisdictional claims in published maps and institutional affiliations. 